\title{
RGD-conjugated rod-like viral nanoparticles on 2D scaffold improve bone differentiation of mesenchymal stem cells
}

\author{
Pongkwan Sitasuwan ${ }^{1,2}$, L. Andrew Lee ${ }^{1,2}$, Kai Li ${ }^{1,3}$, Huong Giang Nguyen ${ }^{1,4}$ and Qian Wang ${ }^{1 *}$ \\ ' Department of Chemistry and Biochemistry, University of South Carolina, Columbia, SC, USA \\ 2 Integrated Micro-Chromatography Systems, Columbia, SC, USA \\ ${ }^{3}$ Weifang Entry-Exit Inspection and Quanrantine Bureau, Weifang, Shandong, China \\ ${ }^{4}$ Department of Chemistry, The Institute of Catalysis for Energy Processes, Northwestern University, Evanston, IL, USA
}

\section{Edited by:}

Carissa M. Soto, Naval Research

Laboratory, USA

\section{Reviewed by:}

Shelli Renee McAlpine, University of New South Wales, Australia

Remigiusz Adam Serwa, Imperial

College London, UK

*Correspondence:

Qian Wang, Department of

Chemistry and Biochemistry,

University of South Carolina, 631

Sumter Street, Columbia, SC 29208,

USA

e-mail:wang263@mailbox.sc.edu
Viral nanoparticles have uniform and well-defined nano-structures and can be produced in large quantities. Several plant viral nanoparticles have been tested in biomedical applications due to the lack of mammalian cell infectivity. We are particularly interested in using Tobacco mosaic virus (TMV), which has been demonstrated to enhance bone tissue regeneration, as a tunable nanoscale building block for biomaterials development. Unmodified TMV particles have been shown to accelerate osteogenic differentiation of adult stem cells by synergistically upregulating bone morphogenetic protein 2 (BMP2) and integrin-binding bone sialoprotein (IBSP) expression with dexamethasone. However, their lack of affinity to mammalian cell surface resulted in low initial cell adhesion. In this study, to increase cell binding capacity of TMV based material the chemical functionalization of TMV with arginine-glycine-aspartic acid (RGD) peptide was explored. An azide-derivatized RGD peptide was "clicked" to tyrosine residues on TMV outer surface via an efficient copper(I) catalyzed azide-alkyne cycloaddition (CuAAC) reaction. The ligand spacing is calculated to be $2-4 \mathrm{~nm}$, which could offer a polyvalent ligand clustering effect for enhanced cell receptor signaling, further promoting the proliferation and osteogenic differentiation of bone marrow-derived mesenchymal stem cells (BMSCs).

Keywords: viral nanoparticles, RGD peptide, click chemistry, osteogenesis, bone mesenchymal stem cells

\section{INTRODUCTION}

Plant viral nanoparticles are meta-stable, readily available, monodisperse, and structurally uniform bionanoparticles. Such plant-derived viral particles have gained great interest in nanoand biomedical applications. Tobacco mosaic virus (TMV) is among the most commonly used plant viruses, having a rodshape measuring $300 \mathrm{~nm}$ in length and $18 \mathrm{~nm}$ in diameter (Figure 1A). The viral capsid consists of 2130 identical coat protein subunits assembled in a helical structure around the single stranded genomic RNA. The production of TMV is cost effective and the resulting viral particles are highly uniform in size. TMV nanoparticles have been demonstrated as powerful building blocks that can be efficiently functionalized via both genetic (Jiang et al., 2006; McCormick et al., 2006; Lee et al., 2012b) and chemical (Schlick et al., 2005; Bruckman et al., 2008) modifications. Due to its identical subunits and regular structure, the same modification occurs on each individual subunit to yield a polyvalent and monodisperse display of ligands within a single TMV particle.

The tripeptide arginine-glycine-aspartic acid (RGD) present in many adhesive proteins in the extracellular matrix (ECM) is a well-known general cell recognition motif via the cell surface integrin receptors (Ruoslahti and Pierschbacher, 1987). These proteins include fibronectin, vitronectin, osteopontin, collagen, thrombospondin, fibrinogen, and von Willebrand factor (Ruoslahti and Pierschbacher, 1987). Generally, the incorporation of RGD sequence into artificial scaffolds increases initial cell adhesion to the scaffold and cell spreading, thus improving tissue regeneration process. It has been suggested that the spacing between RGD motifs needs to be less than $440 \mathrm{~nm}$ to mediate fibroblast adhesion and spreading and less than $140 \mathrm{~nm}$ to mediate focal adhesion assembly (Massia and Hubbell, 1991). Later, it was discovered that the RGD cluster spacings have a threshold less than $60 \mathrm{~nm}$ in order for NR6 fibroblasts to form focal adhesion and stress fiber (Maheshwari et al., 2000). Moreover, the threshold spacings are lower (closer) if there is less RGD clustering. In other words, at the same surface RGD density, the surface with RGD clusters present would provide greater cell adhesion strength (Maheshwari et al., 2000). Another study illustrated that integrinmediated signaling requires RGD spacing of less than $58 \mathrm{~nm}$ (Cavalcanti-Adam et al., 2006). A more recent study showed that focal adhesion complexes between cell-membrane integrins and cytoskeleton, responsible for signal transduction from external stimuli to the cell, were formed when RGD spacing is less than $44 \mathrm{~nm}$ in endothelial cells (Le Saux et al., 2011). Specifically in the case of osteogenesis, there are several studies illustrating that the incorporation of RGD sequence into biomaterials improved bone differentiation and regeneration (Shin et al., 2004, 2005; Anderson et al., 2010; Peng et al., 2011; Qu et al., 2011). Especially, it was recently emphasized that a local clustering of RGD ligands is more essential than global RGD density (Deeg et al., 2011; Wang et al., 2013b). This clustering effect is believed to occur at an integrin-binding spacing less than an integrin itself, which has a size of $8-12 \mathrm{~nm}$. 

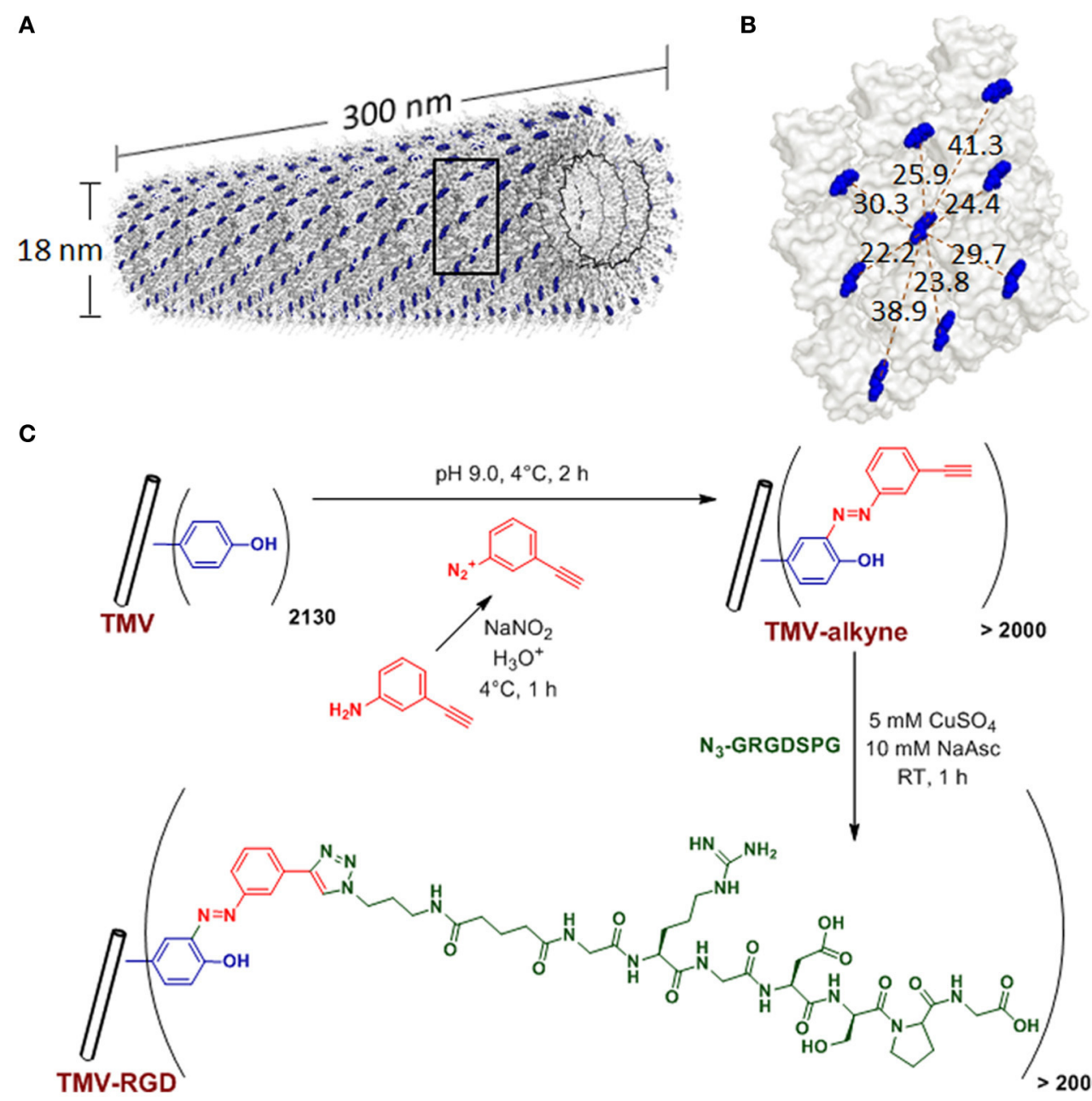

$\mathrm{RT}, 1 \mathrm{~h}$

FIGURE 1 | TMV structure and bioconjugation scheme. (A) Computer reconstructed image showing TMV structure using PyMOL with coordinates from Protein Data Bank. The single stranded RNA inside TMV particle is represented by the black helix. The tyrosine 139 (Y139) residues of individual TMV coat proteins subunits are colored in blue while all other amino acid residues are washed out in gray. (B) An enlarged portion of TMV coat protein [from the boxed area in (A)], showing possible distances (dashed red lines, measured in Angstroms) among the blue Y139. (C) Scheme of the TMV bioconjugation reaction to tether RGD peptides via CuAAC reactions to alkyne-functionalized $\mathrm{Y} 139$ residues.
Many viral nanoparticles have been employed to achieve RGD-displaying clustering, such as M13 bacteriophage (Souza et al., 2006; Rong et al., 2008; Merzlyak et al., 2009; Chung et al., 2010; Wang et al., 2013a), Cowpea mosaic virus (Hovlid et al., 2012), Turnip yellow mosaic virus (Zeng et al., 2011; Zan et al., 2012), including genetically modified TMV with RGD peptides (Luckanagul et al., 2012; Lee et al., 2012a,b). However, to guarantee a successful assembly of final mutant TMV particles, TMV can only tolerate limited sequence diversity and length of the genetic peptide insertion (Lee et al., 2012b). Therefore, we explore the feasibility of TMV functionalization with the copper catalyzed alkyne-azide cycloaddition (CuAAC) reaction to display RGD peptides. In addition, the influence of RGD-presenting TMV, where RGD clustering is present (RGD spacing of 2-4 nm) (Figure 1B), on the osteogenic potential of bone marrow derived mesenchymal stem cells (BMSCs) is investigated.

\section{MATERIALS AND METHODS TMV ISOLATION, BIOCONJUGATION, AND CHARACTERIZATION}

TMV was isolated and purified according to a protocol previously reported (Kaur et al., 2010a,b). The schematic representation of TMV bioconjugation is shown in Figure 1C. The RGD-azide peptide was synthesized using solid-phase peptide synthesis. The peptides were purified with FPLC and characterized by LC/ESI mass spectrometry. The CuAAC reaction to modify tyrosine residues on the exterior surface of TMV is performed according to protocols established by Schlick et al. (2005) and Bruckman et al. (2008) with slight modifications. Briefly, diazonium salt was synthesized by mixing 16 parts of $0.3 \mathrm{M} p$-toluenesulfonic acid, three parts of $0.67 \mathrm{M} 3$-aminophenylacetylene, and one part of $3 \mathrm{M}$ sodium nitrite as published previously (Schlick et al., 2005). TMV was treated with 25 molar excess of the diazonium salt generated in situ from 3-aminophehylacetylene at $4^{\circ} \mathrm{C}$ in a $\mathrm{pH} 9.0$ buffer solution to form alkyne grafted TMV particle. CuAAC reaction 
was used to conjugate RGD-azide peptide to TMV particle (Wang et al., 2003). The CuAAC reaction was done with concentration of TMV-alkyne at $3 \mathrm{mg} / \mathrm{mL}$ and peptide-azide at $4 \mathrm{mg} / \mathrm{mL}$ in Tris $\mathrm{HCl}$ buffer $(10 \mathrm{mM}, \mathrm{pH} 7.8)$, in the presence of $5 \mathrm{mM}$ copper (II) sulfate and $10 \mathrm{mM}$ sodium acetate. After $1 \mathrm{~h}$ incubation at room temperature, TMV-RGD was purified via a $10-50 \%$ sucrose gradient from which the light scattering region was collected. The modified virus was then pelleted using ultracentrifugation at $160,000 \mathrm{~g}$ for $2.5 \mathrm{~h}$ at $4^{\circ} \mathrm{C}$. The pellet was dissolved in potassium phosphate buffer (10 mM, pH 7.4). MALDI-TOF mass spectrometry was used to confirm the modifications. The integrity of modified TMV particles was confirmed by AFM and TEM. The virus solutions were dialyzed against water prior to substrate coating.

\section{PREPARATION OF VIRUS COATED SUBSTRATES}

For cell culture experiments, 3-aminopropyltriethoxysilane (APTES) coated slides (Lab Scientific Inc.) were cut into $1.5 \mathrm{~cm}^{2}$ wafers. The wafers were washed with ethanol before use. For virus coating, each wafer was coated with $0.2 \mathrm{~mL}$ of $0.2 \mathrm{mg} / \mathrm{mL}$ TMV or TMV-RGD solution diluted in water and the coated substrates were dried overnight in a sterile biosafety cabinet. The virus coverage on the wafers was characterized using tapping-mode AFM images using a NanoScope IIIA MultiMode AFM (Veeco). Si tips with a resonance frequency of approximately $300 \mathrm{kHz}$, a spring constant of about $40 \mathrm{~N} \mathrm{~m}^{-1}$ and a scan rate of $1.0 \mathrm{~Hz}$ were used.

\section{BMSC ISOLATION AND EXPANSION}

Primary BMSCs were isolated from the bone marrow of young adult $80 \mathrm{~g}$ male Wister rats (Harlan Sprague Dawley, Inc.). The procedures were performed in accordance with the guidelines for animal experimentation by the Institutional Animal Care and Use Committee, School of Medicine, University of South Carolina. Cells were maintained in growth medium [DMEM supplemented with $10 \%$ fetal bovine serum (FBS), penicillin $(100 \mathrm{U} / \mathrm{mL})$, streptomycin $(100 \mu \mathrm{g} / \mathrm{mL})$, and amphotericin B $(250 \mathrm{ng} / \mathrm{mL})]$ and passaged no more than four times after isolation. To induce osteogenesis, growth media was replaced with osteogenic media consisting of DMEM supplemented with 10\% FBS, penicillin $(100 \mathrm{U} / \mathrm{mL})$, streptomycin $(100 \mu \mathrm{g} / \mathrm{mL})$, amphotericin $\mathrm{B}$ $(250 \mathrm{ng} / \mathrm{mL}), 10 \mathrm{mM}$ sodium $\beta$-glycerophosphate, $\mathrm{L}$-ascorbic acid 2-phosphate $(50 \mu \mathrm{g} / \mathrm{mL})$, and $10^{-8} \mathrm{M}$ dexamethasone. Media was replenished every $3-4$ days.

\section{CELL PROLIFERATION}

Substrates coated with TMV and TMV-RGD were seeded with $4 \times 10^{4}$ cells per substrate and cells were allowed to attach overnight in growth media. The media was then replaced with osteogenic media and cultured for 22 days. CellTiter Blue ${ }^{\circledR}$ assay (Promega) was used to determine number of cells at 0, 2, 4, 9, 12,16 , and 22 days after osteogenic induction. Cell proliferation was determined by normalizing CellTiter Blue fluorescence intensities against initial signal intensity on day 0 , which is the day of osteogenic induction.

\section{QUANTITATIVE REAL-TIME RT-PCR ANALYSIS (RT-qPCR)}

Virus coated wafers were seeded with $4 \times 10^{4}$ cells per wafer and cells were allowed to attach overnight in growth media. The unseeded cells were used as a control to normalize the change in gene expression. The media was replaced with osteogenic media and cultured for 7, 14, and 21 days. The cell cultures were terminated at these time points and total RNA was extracted using RNeasy mini purification kit (Qiagen). The quality and quantity of the extracted RNA was analyzed using Bio-Rad Experion (BioRad Laboratories) and was reverse transcribed by using $\mathrm{qScript} \mathrm{t}^{\mathrm{TM}}$ cDNA Supermix (Quanta Biosciences). RT-qPCR (iQ5 real-time PCR detection system Bio-Rad Laboratories) was done by the method described as: 60 cycles of PCR $\left(95^{\circ} \mathrm{C}\right.$ for $20 \mathrm{~s}, 58^{\circ} \mathrm{C}$ for $15 \mathrm{~s}$, and $72^{\circ} \mathrm{C}$ for $15 \mathrm{~s}$ ), after initial denaturation step of $5 \mathrm{~min}$ at $95^{\circ} \mathrm{C}$, by using $12.5 \mu \mathrm{L}$ of iQ5 SYBR Green I Supermix, 2 $\mathrm{pmol} / \mu \mathrm{L}$ of each forward and reverse primers and $0.5 \mu \mathrm{L}$ cDNA templates in a final reaction volume of $25 \mu \mathrm{L}$. Glyceraldehyde 3-phosphate dehydrogenase (GAPDH) was used as the housekeeping gene. Data collection was enabled at $72^{\circ} \mathrm{C}$ in each cycle and $\mathrm{C}_{\mathrm{T}}$ (threshold cycle) values were calculated using the iQ5 optical system software version 2.1. The expression levels of differentiated genes and undifferentiated genes were calculated using Pfaffl's method (M. W. Pfaffl, G. W. Horgan, and L. Dempfle, Relative expression software tool) for group-wise comparison and statistical analysis of relative expression results in real-time PCR, using GAPDH as the reference gene. Quantification of gene expression was based on the $\mathrm{C}_{\mathrm{T}}$ value for each sample which was calculated as the average of three replicate measurements for each sample analyzed. "Pair Wise Fixed Reallocation Randomization Test" was performed on each sample and a value of $p<0.05$ was regarded as significant. The primers used for RT-qPCR are shown in Figure S1.

\section{ALKALINE PHOSPHATASE ACTIVITY}

After 14 days in osteogenic cultures, CellTiter Blue ${ }^{\circledR}$ assay (Promega) was used to determine number of cells in each sample $1 \mathrm{~h}$ prior to cell fixation. BMSCs seeded on TMV and TMV-RGD were fixed with $4 \%$ paraformaldehyde for $15 \mathrm{~min}$ at room temperature. To determine alkaline phosphatase (ALP) activity, each fixed samples were incubated in $500 \mu \mathrm{L}$ of 1 -Step $p$-nitrophenyl phosphate solution (Thermo Scientific) for $15 \mathrm{~min}$ at room temperature. Then the solution was transferred to a new microfuge tube with $250 \mu \mathrm{L}$ of $2 \mathrm{~N} \mathrm{NaOH}$ and the absorbance at $405 \mathrm{~nm}$ was measured. The measured ALP activity from each sample was normalized to the corresponding cell number.

\section{ALIZARIN RED STAINING}

To visualize calcium deposition and to confirm osteogenic differentiation, fixed samples at day 14 were stained with $0.1 \%$ Alizarin red solution (Sigma-Aldrich) pH 4.1-4.5 for $30 \mathrm{~min}$ in the dark. The samples were washed with water $(18.2 \mathrm{M} \Omega)$ prior to imaging.

\section{RESULTS}

The tyrosine residues (Y139) of TMV are viable for chemical ligation using electrophilic substitution reaction at the orthoposition of the phenol ring with diazonium salts (Schlick et al., 2005). TMV subunits are assembled in a highly regular helical structure, which resulted in uniform spacing between two subunits down to a nanometer scale. From coordinates provided by Protein Data Bank, the distance between neighboring Y139 
residues of TMV coat proteins is calculated to be $2-4 \mathrm{~nm}$ apart as shown in Figure 1B. The CuAAC reaction has been confirmed to be a very efficient way to display functional groups on TMV in a controllable manner (Bruckman et al., 2008). Following the reported protocol (Schlick et al., 2005; Bruckman et al., 2008). We first prepared the alkyne derived TMV particles (Figure 1C). As shown in the MALDI-TOF MS analysis (Figure 2A), the peak of the coat protein $(\mathrm{m} / \mathrm{z} 17534)$ disappeared after the diazonium coupling resulting in the TMV-alkyne product (m/z 17664), consistent with a previous report (Lee et al., 2012b). Similarly, the MALDI-TOF MS analysis indicated the correct mass shift for TMV-RGD confirmed the completion of the sequential CuAAC reaction (Figure 2A). The integrity of TMV-RGD was confirmed by AFM and TEM (Figure 2B). AFM images illustrated that the majority of TMV-RGD remained rod-shaped particles after the bioconjugation. The diameter observed under TEM ranged from 15-20 nm with lengths measuring approximately $300 \mathrm{~nm}$, indicating the particles are intact after the two-step CuAAC reaction to Y139 (Figure 2B).

The effect of RGD-displaying TMV, as a polyvalent scaffold, on bone differentiation was explored. It has been demonstrated that unmodified TMV substrate accelerated osteogenesis by 7 days compared to standard tissue culture polystyrene (TCPS) control (Kaur et al., 2010a). The chemical incorporation of phosphate functional groups to TMV further enhanced bone differentiation of BMSCs (Kaur et al., 2010b). However, the interaction between BMSCs and TMV substrates were weak since the focal adhesion

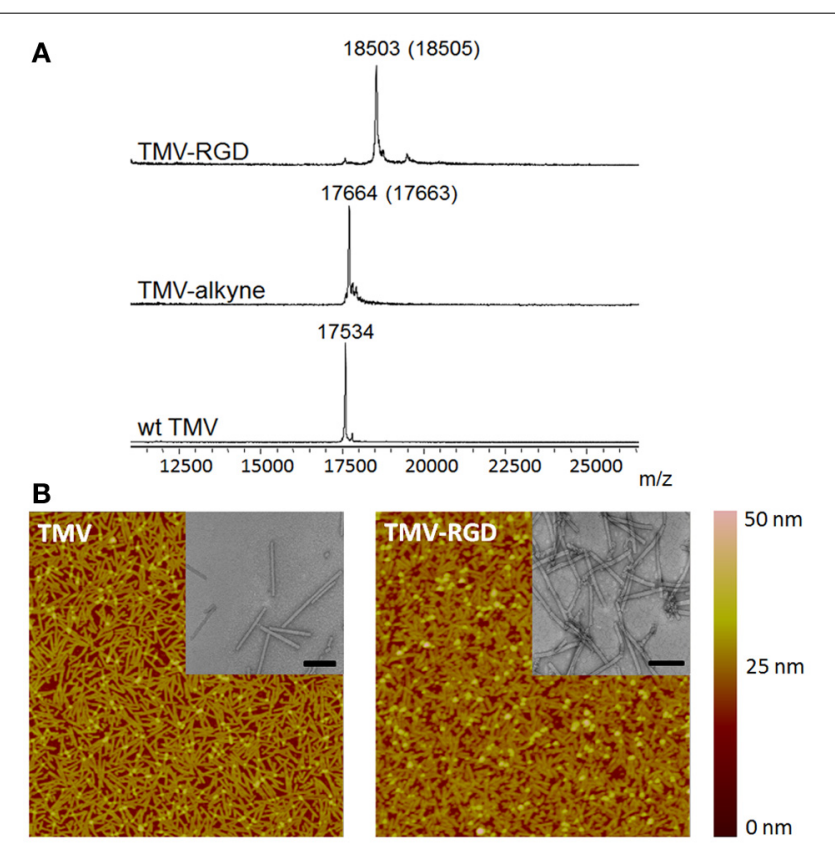

FIGURE 2 | Characterization of TMV particles. (A) MALDI-TOF MS spectra of the subunit protein of wild type TMV (17534 m/z), TMV-alkyne ( $17664 \mathrm{~m} / \mathrm{z})$, and the CuAAC reaction product TMV-RGD (18503 m/z). The numbers in parentheses refer to the theoretical masses. (B) The morphology of TMV particles before (TMV) and after (TMV-RGD) bioconjugation visualized by AFM and TEM (insets). Scan areas of AFM are $5 \times 5 \mu \mathrm{m}$; and scale bars of TEM are $200 \mathrm{~nm}$. complexes were found to be significantly smaller than the control (Sitasuwan et al., 2012). Since RGD ligand is known to promote cell attachment, the incorporation of RGD motifs into TMV based substrate is expected to increase the initial cell adhesion.

Prior to cell culture experiments, TMV and TMV-RGD were dialyzed several times against ultrapure water, due to concerns that residual $\mathrm{Cu}^{\mathrm{I}}$ from the $\mathrm{CuAAC}$ reaction will affect cell viability. Optical images after $24 \mathrm{~h}$ of cell seeding in Figure $3 \mathrm{~A}$ revealed that BMSCs can adhere and spread on both TMV and TMV-RGD substrates. There were slightly more cells visualized on TMV-RGD compared to TMV coated surface. The numbers of adherent cells were calculated to elucidate the result in a quantitative manner (Figure 3B). As expected, the average cell numbers on TMV-RGD was higher than that of TMV. To verify that TMV-RGD does not have cytotoxicity from residual $\mathrm{Cu}^{\mathrm{I}}$, the proliferation of BMSCs on both virus scaffolds was examined over 22 days in osteogenic conditions (Figure 3C). The proliferation percentage of each sample was calculated based on the initial cell attachment as a $100 \%$. BMSCs proliferated comparably well on both virus substrates, thus TMV-RGD did not exhibit any cytotoxicity to the in vitro cell culture.

The differentiation potential of BMSCs was studied in order to substantiate the effect of RGD incorporation on osteogenesis. First, osteo-specific gene expression levels were quantified by RT-qPCR (Figure 4A). The expression levels are presented as fold change compared to BMSCs at day 0 . There was no significant difference in the gene expression levels of alkaline phosphatase $(A L P L)$, osteonectin $(S P A R C)$, and osteopontin (SPP1) over the 3 weeks. Another osteo-specific gene examined is osteocalcin $(B G L A P)$, the most common marker of mature osteoblast, as this protein is only synthesized by fully differentiated osteoblasts (Fujisawa and Tamura, 2012). BGLAP is rich in acidic amino acids that are responsible for its high affinity to calcium ions (Fujisawa and Tamura, 2012), which are eventually accumulated in mineralized bone matrix by binding specifically to hydroxyapatite crystals (Owen et al., 1990). It has been documented that BGLAP, which is normally peaked at day 21 on standard tissue culture plate substrate, is peaked at day 14 when BMSCs are grown on TMV scaffold suggesting that TMV substrates accelerate the bone differentiation process by 7 days (Kaur et al., 2010a). The gene expression analysis of BMSCs on unmodified TMV scaffolds in Figure 4A was in agreement with the previous report (Kaur et al., 2010a), where BGLAP gene expression level was peaked at day 14 indicating a complete mineralization of mature osteoblasts. As a comparison, the incorporation of RGD peptide into TMV subunits also significantly increased BGLAP gene expression level at day 14 (Figure 4A). The gene expression level of integrin-binding bone sialoprotein $(I B S P)$, a secreted ECM protein required for hydroxyapatite formation as well as collagen binding in mineralized tissues (Ogata, 2008), was also evaluated. IBSP is synthesized just before calcification (Fujisawa and Tamura, 2012) and real time PCR results from the previous study indicated that BMSCs on TMV substrates had significantly higher IBSP mRNA expression within $24 \mathrm{~h}$ while there was no change in IBSP mRNA expression levels in BMSCs on TCPS control (Sitasuwan et al., 2012). In this experiment, IBSP expression levels in cells on both TMV and TMV-RGD were highly upregulated during the 


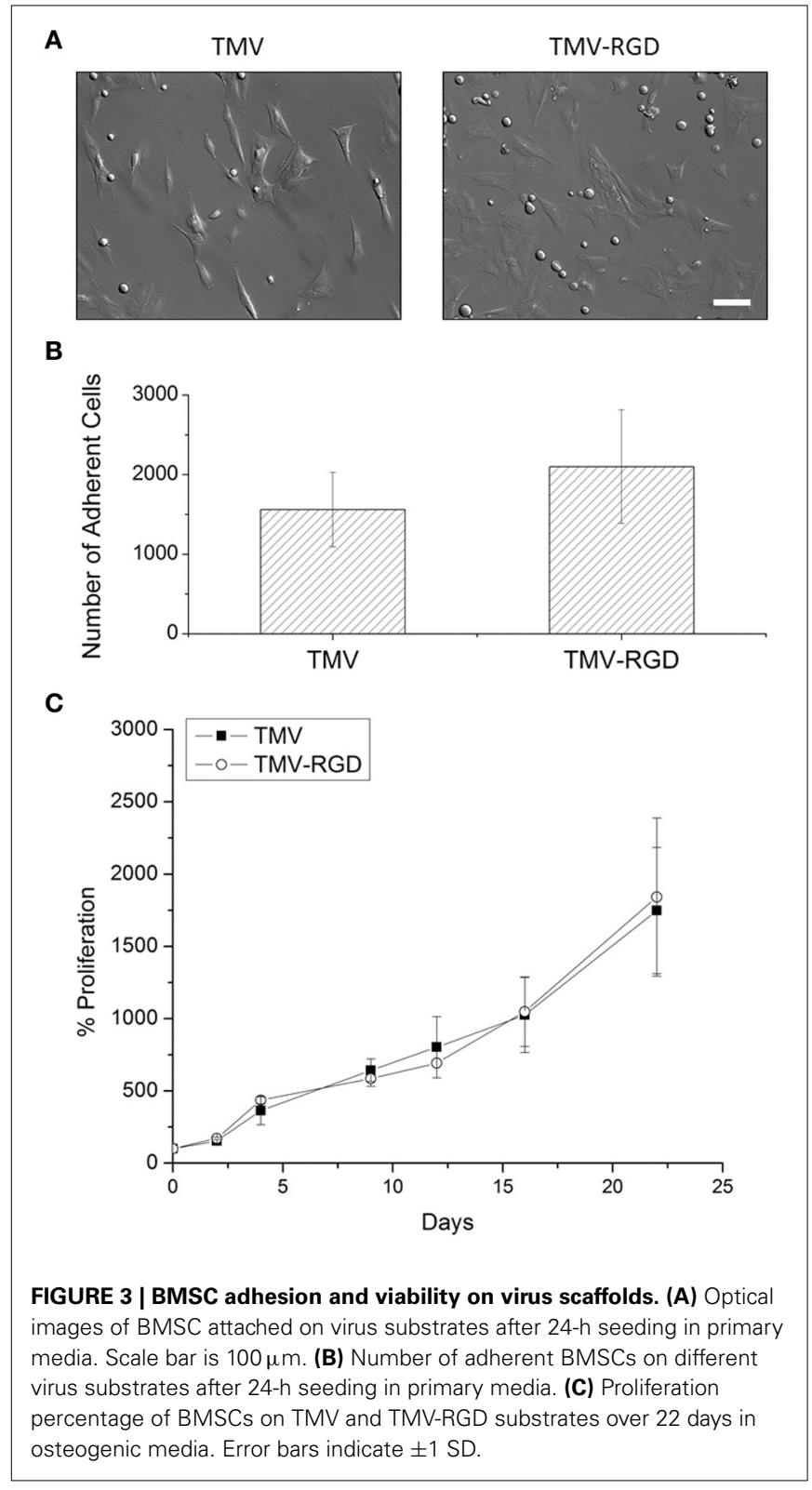

culture period (Figure 4A). However, BMSCs grown on TMVRGD scaffolds expressed remarkably higher level of IBSP mRNA at day 21 when compared to those on native TMV scaffolds at the same time (Figure 4A).

In addition to the analysis of osteo-specific gene expressions, ALP activity was assessed. ALP is an early marker of osteogenesis and its activity mediates matrix mineralization. Although there was no difference in ALPL mRNA expressions at day 14 for cells grown on TMV compared to those on TMV-RGD as shown in Figure 4A, ALP enzyme activity assay showed a slight increase in BMSCs grown on TMV-RGD (Figure 4B). The staining for calcium deposition was also performed at day 14. A stronger staining was observed on TMV-RGD samples suggesting higher mineralization level (Figure 4C). This observation could be supported by previously mentioned increases in both BGLAP and IBSP mRNA expression levels (Figure 4A), possibly facilitating the formation of hydroxyapatite crystals leading to mineralized matrix.

\section{DISCUSSION}

TMV has previously been shown to be an effective scaffold that accelerates bone differentiation of stem cells when coated on a 2D substrate and provides support for cell differentiation in 3D alginate hydrogels (Kaur et al., 2010a,b; Luckanagul et al., 2012; Sitasuwan et al., 2012). While the underlying mechanism is still unclear, the level of the potent osteogenic induction protein, bone morphogenetic protein 2 (BMP2), was significantly increased within $24 \mathrm{~h}$ for cells cultured on substrates with TMV coating compared to cells cultured on uncoated substrates or cells supplemented with TMV in suspension (Sitasuwan et al., 2012). One possible interpretation of this observation is that the topographical features created by TMV coating, compared to TMV in solution, plays a major role in the accelerated osteogenic differentiation.

Cells are capable of sensing the surrounding microenvironment, which provides both biochemical and biophysical cues, leading to downstream signaling cascades responsible for diverse cellular processes, such as adhesion, migration, proliferation, and apoptosis (Curtis and Wilkinson, 1997). For example, the nanoscale roughness of titanium surface implant can positively affect implant integration and bone differentiation (Lossdörfer et al., 2004; Mozumder et al., 2012; Olivares-Navarrete et al., 2012; Zhuang et al., 2012). In addition, the incorporation of growth factors (Crouzier et al., 2011; Wang et al., 2011; Kopf et al., 2012; Lee et al., 2013), adhesion ligands (Shin et al., 2005; Duggal et al., 2009; Qu et al., 2011), and osteoinductive compounds (Shu et al., 2003; Verma et al., 2010; Hao et al., 2011; Cameron et al., 2013 ) into biomaterial surface can further accelerate the bone formation process. Given the lack of affinity of native TMV viral particles to mammalian cell surface, which resulted in low initial cell adhesion (Sitasuwan et al., 2012), we hypothesized that combining the topological features offered by TMV with cellular adhesion molecules could synergistically enhance the bone formation process of stem cells.

In our previous study, we reported the genetic incorporation of RGD peptides on the coat protein of TMV particles and the resulting mutant virus could enhance the adhesion of BMSCs (Lee et al., 2012b) and accelerate the stem cell differentiation in serum free, chemically defined osteogenic media (Lee et al., 2012a). However, the genetic insertion suffers from the limited length and sequence diversity of the fusion peptides. To guarantee a successful assembly of final mutant TMV particles, TMV can only tolerate limited sequence diversity and length of the genetic peptide insertion. In this work, we demonstrate the feasibility of modulating mesenchymal stem cell differentiation on TMV-based scaffolds modified by CuAAC reaction. TMV was successfully modified with more than 95\% conversion and the integrity of the virus particles was preserved. Scaffolds coated with TMV-RGD slightly improved initial BMSC adhesion, while maintaining the same cell proliferation rate with those coated with native TMV. The osteogenic differentiation of BMSCs was enhanced on TMV-RGD substrates since an increase in BGLAP and IBSP gene expression levels as well as mineralization level 

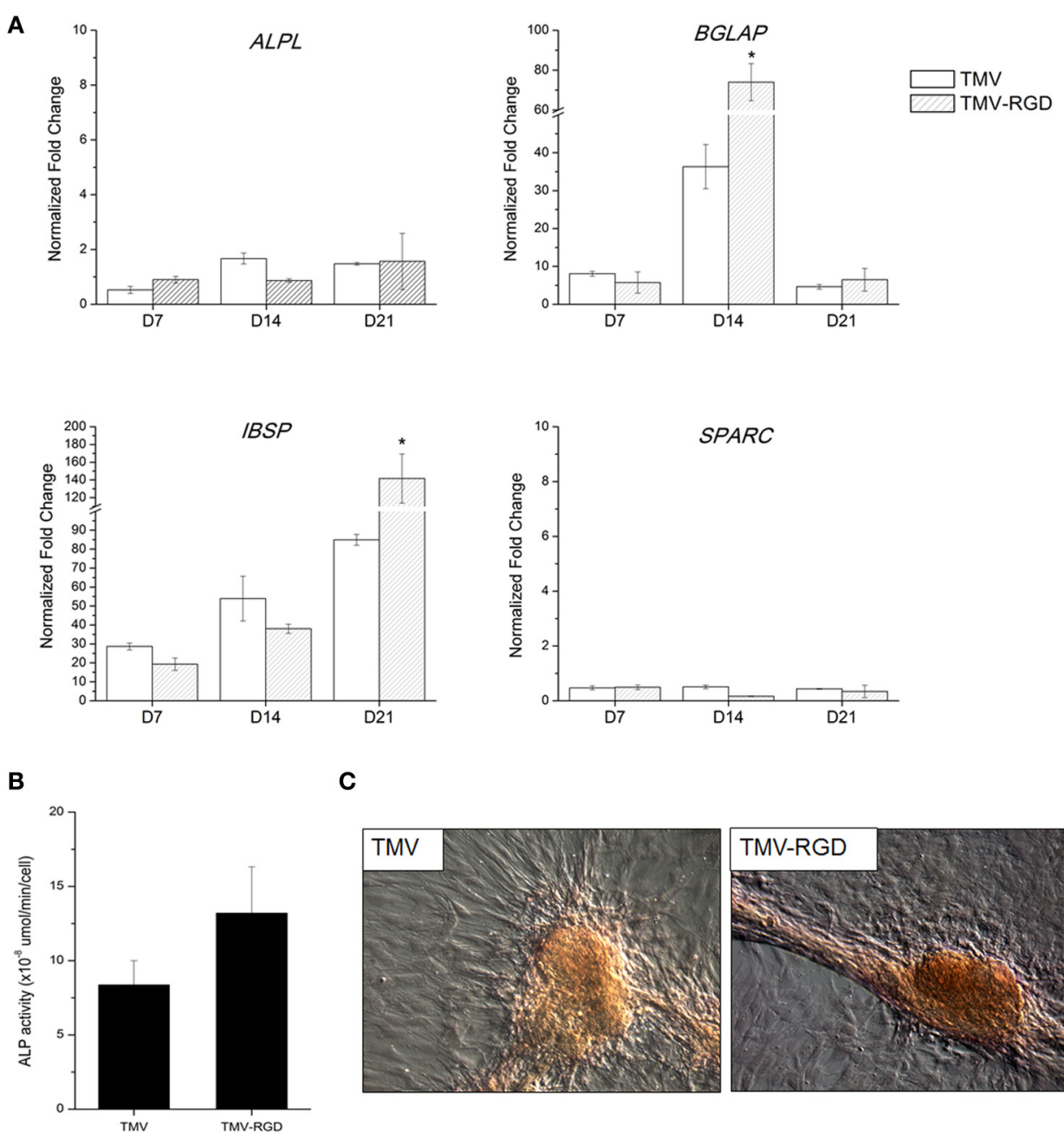

C

FIGURE 4 | Osteogenic differentiation of BMSCs on TMV and TMV-RGD substrates. (A) Osteo-specific gene expression profiles of BMSCs on TMV and TMV-RGD under osteogenic conditions over 21 days. For each sample, the profiles show 3 time points at 7,14, and 21 days. BMSCs on TMV-RGD substrates have significantly higher BGLAP at day 14 and IBSP at day 21 when compared with unmodified TMV substrates. Error bars indicate \pm 1 SD.
${ }^{*} p<0.05$. (B) Alkaline phosphatase activity of cells on TMV and TMV-RGD at day 14. BMSCs on TMV-RGD substrates have a slight increase in enzyme activity compared to cells on TMV. However, the difference is not statistically significant. (C) Optical images of Alizarin red S staining of cells cultured for 14 days on TMV or TMV-RGD substrate showing calcium deposition in red colour. was observed, similar as TMV-RGD genetic mutant. However, the chemically tailored TMV particles have shown greater stability than TMV-RGD mutant particles.

It was expected that the displayed RGD peptides on TMV particles could lead to significantly greater cell attachment. However, it only facilitated a slight increase in the initial BMSC adhesion. A possible explanation is that TMV-RGD tends to aggregate leading to hindered ligand display. A precipitate was observed after the CuAAC reaction to functionalize TMV-alkyne with RGD peptide. Similarly, the rapid decomposition and aggregation of an icosahedral plant virus was previously observed when the virus is decorated with triazole with the presence of free copper ions in solution (Wang et al., 2003). Future studies will focus on controlling ligand density and using a variety of ligands including small molecules and other peptides on viral scaffold to study structure-property relationship and modulate cell behavior. It is also important that a recent development of copper-free Click reaction (Lallana et al., 2011) may provide an alternative approach to chemically modify TMV without a concern about $\mathrm{Cu}^{\mathrm{I}}$ contamination.

\section{ACKNOWLEDGMENTS}

This work was supported by the US NSF (CHE-0748690), the USC ASPIRE Award, the USC Science Undergraduate Research Fellowship Program (to Huong Giang Nguyen) and the Camille Dreyfus Teacher Scholar Award.

\section{SUPPLEMENTARY MATERIAL}

The Supplementary Material for this article can be found online at: http://www.frontiersin.org/journal/10.3389/fchem.2014. 00031/abstract 
Figure S1 | Primers used for RT-qPCR to measure gene expression levels. $A L P L$, alkaline phosphatase; BGLAP, osteocalcin; IBSP, integrin-binding sialoprotein; SPARC, osteonectin; SPP1, osteopontin.

\section{REFERENCES}

Anderson, J. M., Vines, J. B., Patterson, J. L., Chen, H., Javed, A., and Jun, H.-W. (2010). Osteogenic differentiation of human mesenchymal stem cells synergistically enhanced by biomimetic peptide amphiphiles combined with conditioned medium. Acta. Biomater. 7, 675-682. doi: 10.1016/j.actbio.2010.08.016

Bruckman, M. A., Kaur, G., Lee, L. A., Xie, F., Sepulveda, J., Breitenkamp, R., et al. (2008). Surface modification of tobacco mosaic virus with "Click" chemistry. Chembiochem. 9, 519-523. doi: 10.1002/cbic.200700559

Cameron, K., Travers, P., Chander, C., Buckland, T., Campion, C., and Noble, B. (2013). Directed osteogenic differentiation of human mesenchymal stem/precursor cells on silicate substituted calcium phosphate. J. Biomed. Mater. Res. A. 101A, 13-22. doi: 10.1002/jbm.a.34261

Cavalcanti-Adam, E. A., Micoulet, A., Blümmel, J., Auernheimer, J., Kessler, H., and Spatz, J. P. (2006). Lateral spacing of integrin ligands influences cell spreading and focal adhesion assembly. Eur. J. Cell Biol. 85, 219-224. doi: 10.1016/j.ejcb.2005.09.011

Chung, W.-J., Merzlyak, A., Yoo, S. Y., and Lee, S.-W. (2010). Genetically engineered liquid-crystalline viral films for directing neural cell growth. Langmuir 26, 9885-9890. doi: 10.1021/la100226u

Crouzier, T., Sailhan, F. D. R., Becquart, P., Guillot, R., Logeart-Avramoglou, D., and Picart, C. (2011). The performance of BMP-2 loaded TCP/HAP porous ceramics with a polyelectrolyte multilayer film coating. Biomaterials 32, 7543-7554. doi: 10.1016/j.biomaterials.2011.06.062

Curtis, A., and Wilkinson, C. (1997). Topographical control of cells. Biomaterials 18, 1573-1583. doi: 10.1016/s0142-9612(97)00144-0

Deeg, J. A., Louban, I., Aydin, D., Selhuber-Unkel, C., Kessler, H., and Spatz, J. P. (2011). Impact of local versus global ligand density on cellular adhesion. Nano Lett. 11, 1469-1476. doi: 10.1021/nl104079r

Duggal, S., Fronsdal, K. B., Szoke, K., Shahdadfar, A., Melvik, J. E., and Brinchmann, J. E. (2009). Phenotype and gene expression of human mesenchymal stem cells in alginate scaffolds. Tissue Eng. A. 15, 1763-1773. doi: 10.1089/ten.tea.2008.0306

Fujisawa, R., and Tamura, M. (2012). Acidic bone matrix proteins and their roles in calcification. Front. Biosci. 17, 1891-1903. doi: 10.2741/4026

Hao, J., Kuroda, S., Ohya, K., Bartakova, S., Aoki, H., and Kasugai, S. (2011). Enhanced osteoblast and osteoclast responses to a thin film sputtered hydroxyapatite coating. J. Mater. Sci. Mater. Med. 22, 1489-1499. doi: 10.1007/s10856011-4329-0

Hovlid, M. L., Steinmetz, N. F., Laufer, B., Lau, J. L., Kuzelka, J., Wang, Q., et al. (2012). Guiding plant virus particles to integrin-displaying cells. Nanoscale 4, 3698-3705. doi: 10.1039/c2nr30571b

Jiang, L., Li, Q., Li, M., Zhou, Z., Wu, L., Fan, J., et al. (2006). A modified TMVbased vector facilitates the expression of longer foreign epitopes in tobacco. Vaccine 24, 109-115. doi: 10.1016/j.vaccine.2005.09.060

Kaur, G., Valarmathi, M. T., Potts, J. D., Jabbari, E., Sabo-Attwood, T., and Wang, Q. (2010a). Regulation of osteogenic differentiation of rat bone marrow stromal cells on 2D nanorod substrates. Biomaterials 31, 1732-1741. doi: 10.1016/j.biomaterials.2009.11.041

Kaur, G., Wang, C., Sun, J., and Wang, Q. (2010b). The synergistic effects of multivalent ligand display and nanotopography on osteogenic differentiation of rat bone marrow stem cells. Biomaterials 31, 5813-5824. doi: 10.1016/j.biomaterials.2010.04.017

Kopf, J., Petersen, A., Duda, G. N., and Knaus, P. (2012). BMP2 and mechanical loading cooperatively regulate immediate early signalling events in the BMP pathway. BMC Biol. 10:37. doi: 10.1186/1741-7007-10-37

Lallana, E., Riguera, R., and Fernandez-Megia, E. (2011). Reliable and efficient procedures for the conjugation of biomolecules through huisgen azidealkyne cycloadditions. Angew. Chem. Int. Edn. Engl. 50, 8794-8804. doi: 10.1002/anie.201101019

Lee, L. A., Muhammad, S. M., Nguyen, Q. L., Sitasuwan, P., Horvath, G., and Wang, Q. (2012a). Multivalent ligand displayed on plant virus induces rapid onset of bone differentiation. Mol. Pharm. 9, 2121-2125. doi: 10.1021/mp300042t

Lee, L. A., Nguyen, Q. L., Wu, L., Horvath, G., Nelson, R. S., and Wang, Q. (2012b). Mutant plant viruses with cell binding motifs provide differential adhesion strengths and morphologies. Biomacromolecules 13, 422-431. doi: $10.1021 / \mathrm{bm} 2014558$

Lee, S. S., Huang, B. J., Kaltz, S. R., Sur, S., Newcomb, C. J., Stock, S. R., et al. (2013). Bone regeneration with low dose BMP-2 amplified by biomimetic supramolecular nanofibers within collagen scaffolds. Biomaterials 34, 452-459. doi: 10.1016/j.biomaterials.2012.10.005

Le Saux, G., Magenau, A., Böcking, T., Gaus, K., and Gooding, J. J. (2011). The relative importance of topography and RGD ligand density for endothelial cell adhesion. PLoS ONE 6:e21869. doi: 10.1371/journal.pone.0021869

Lossdörfer, S., Schwartz, Z., Wang, L., Lohmann, C. H., Turner, J. D., Wieland, M., et al. (2004). Microrough implant surface topographies increase osteogenesis by reducing osteoclast formation and activity. J. Biomed. Mater. Res. A. 70A, 361-369. doi: 10.1002/jbm.a.30025

Luckanagul, J., Lee, L. A., Nguyen, Q. L., Sitasuwan, P., Yang, X., Shazly, T., et al. (2012). Porous alginate hydrogel functionalized with virus as three-dimensional scaffolds for bone differentiation. Biomacromolecules 13, 3949-3958. doi: 10.1021/bm301180c

Maheshwari, G., Brown, G., Lauffenburger, D. A., Wells, A., and Griffith, L. G. (2000). Cell adhesion and motility depend on nanoscale RGD clustering. J. Cell Sci. 113, 1677-1686.

Massia, S. P., and Hubbell, J. A. (1991). An RGD spacing of $440 \mathrm{~nm}$ is sufficient for integrin alpha V beta 3-mediated fibroblast spreading and $140 \mathrm{~nm}$ for focal contact and stress fiber formation. J. Cell Biol. 114, 1089-1100. doi: 10.1083/jcb.114.5.1089

McCormick, A. A., Corbo, T. A., Wykoff-Clary, S., Nguyen, L. V., Smith, M. L., Palmer, K. E., et al. (2006). TMV-peptide fusion vaccines induce cell-mediated immune responses and tumor protection in two murine models. Vaccine 24, 6414-6423. doi: 10.1016/j.vaccine.2006.06.003

Merzlyak, A., Indrakanti, S., and Lee, S.-W. (2009). Genetically engineered nanofiber-like viruses for tissue regenerating materials. Nano Lett. 9, 846-852. doi: $10.1021 / \mathrm{nl} 8036728$

Mozumder, M. S., Zhu, J., and Perinpanayagam, H. (2012). Titania-polymeric powder coatings with nano-topography support enhanced human mesenchymal cell responses. J. Biomed. Mater. Res. A. 100A, 2695-2709. doi: 10.1002/jbm.a.34199

Ogata, Y. (2008). Bone sialoprotein and its transcriptional regulatory mechanism. J. Periodont. Res. 43, 127-135. doi: 10.1111/j.1600-0765.2007.01014.x

Olivares-Navarrete, R., Gittens, R. A., Schneider, J. M., Hyzy, S. L., Haithcock, D. A., Ullrich, P. F., et al. (2012). Osteoblasts exhibit a more differentiated phenotype and increased bone morphogenetic protein production on titanium alloy substrates than on poly-ether-ether-ketone. Spine J. 12, 265-272. doi: 10.1016/j.spinee.2012.02.002

Owen, T. A., Aronow, M., Shalhoub, V., Barone, L. M., Wilming, L., Tassinari, M. S., et al. (1990). Progressive development of the rat osteoblast phenotype in vitro: Reciprocal relationships in expression of genes associated with osteoblast proliferation and differentiation during formation of the bone extracellular matrix. J. Cell. Physiol. 143, 420-430. doi: 10.1002/jcp.1041430304

Peng, R., Yao, X., and Ding, J. (2011). Effect of cell anisotropy on differentiation of stem cells on micropatterned surfaces through the controlled single cell adhesion. Biomaterials 32, 8048-8057. doi: 10.1016/j.biomaterials.2011.07.035

Qu, Z., Yan, J., Li, B., Zhuang, J., and Huang, Y. (2011). Improving bone marrow stromal cell attachment on chitosan/hydroxyapatite scaffolds by an immobilized RGD peptide. Biomed. Mater. 5:065001. doi: 10.1088/1748-6041/5/6/065001

Rong, J., Lee, L. A., Li, K., Harp, B., Mello, C. M., Niu, Z., et al. (2008). Oriented cell growth on self-assembled bacteriophage M13 thin films. Chem. Commun. (Camb.) 5185-5187. doi: 10.1039/b811039e

Ruoslahti, E., and Pierschbacher, M. D. (1987). New perspectives in cell adhesion: RGD and integrins. Science 238, 491-497.

Schlick, T. L., Ding, Z., Kovacs, E. W., and Francis, M. B. (2005). Dual-surface modification of the tobacco mosaic virus. J. Am. Chem. Soc. 127, 3718-3723. doi: 10.1021/ja046239n

Shin, H., Temenoff, J. S., Bowden, G. C., Zygourakis, K., Farach-Carson, M. C., Yaszemski, M. J., et al. (2005). Osteogenic differentiation of rat bone marrow stromal cells cultured on Arg-Gly-Asp modified hydrogels without dexamethasone and $\beta$-glycerol phosphate. Biomaterials 26, 3645-3654. doi: 10.1016/j.biomaterials.2004.09.050

Shin, H., Zygourakis, K., Farach-Carson, M. C., Yaszemski, M. J., and Mikos, A. G. (2004). Modulation of differentiation and mineralization of marrow stromal cells cultured on biomimetic hydrogels modified with Arg-Gly-Asp containing peptides. J. Biomed. Mater. Res. A. 69A, 535-543. doi: 10.1002/jbm.a.30027 
Shu, R., McMullen, R., Baumann, M. J., and McCabe, L. R. (2003). Hydroxyapatite accelerates differentiation and suppresses growth of MC3T3-E1 osteoblasts. J. Biomed. Mater. Res. A. 67A, 1196-1204. doi: 10.1002/Jbm.A.20021

Sitasuwan, P., Andrew Lee, L., Bo, P., Davis, E. N., Lin, Y., and Wang, Q. (2012). A plant virus substrate induces early upregulation of BMP2 for rapid bone formation. Integr. Biol. 4, 651-660. doi: 10.1039/c2ib20041d

Souza, G. R., Christianson, D. R., Staquicini, F. I., Ozawa, M. G., Snyder, E. Y., Sidman, R. L., et al. (2006). Networks of gold nanoparticles and bacteriophage as biological sensors and cell-targeting agents. Proc. Natl. Acad. Sci. U.S.A. 103, 1215-1220. doi: 10.1073/pnas.0509739103

Verma, D., Katti, K. S., and Katti, D. R. (2010). Osteoblast adhesion, proliferation and growth on polyelectrolyte complex-hydroxyapatite nanocomposites. Philos. Trans. A Math. Phys. Eng. Sci. 368, 2083-2097. doi: 10.1098/rsta.20 10.0013

Wang, J., Wang, L., Li, X., and Mao, C. (2013a). Virus activated artificial ECM induces the osteoblastic differentiation of mesenchymal stem cells without osteogenic supplements. Sci. Rep. 3:1242. doi: 10.1038/srep01242

Wang, Q., Chan, T. R., Hilgraf, R., Fokin, V. V., Sharpless, K. B., and Finn, M. G. (2003). Bioconjugation by copper(I)-catalyzed azide-alkyne [3+2] cycloaddition. J. Am. Chem. Soc. 125, 3192-3193. doi: 10.1021/ja021381e

Wang, X., Oyane, A., Tsurushima, H., Sogo, Y., Li, X., and Ito, A. (2011). BMP-2 and ALP gene expression induced by a BMP-2 gene-fibronectin-apatite composite layer. Biomed. Mater. 6:045004. doi: 10.1088/1748-6041/6/4/045004

Wang, X., Yan, C., Ye, K., He, Y., Li, Z., and Ding, J. (2013b). Effect of RGD nanospacing on differentiation of stem cells. Biomaterials 34, 2865-2874. doi: 10.1016/j.biomaterials.2013.01.021

Zan, X., Sitasuwan, P., Powell, J., Dreher, T. W., and Wang, Q. (2012). Polyvalent display of RGD motifs on turnip yellow mosaic virus for enhanced stem cell adhesion and spreading. Acta. Biomater. 8, 2978-2985. doi: 10.1016/j.actbio.2012.04.027

Zeng, Q., Saha, S., Lee, L. A., Barnhill, H., Oxsher, J., Dreher, T., et al. (2011). Chemoselective modification of turnip yellow mosaic virus by $\mathrm{Cu}(\mathrm{I})$ Catalyzed azide-alkyne 1,3-dipolar cycloaddition reaction and its application in cell binding. Bioconjug. Chem. 22, 58-66. doi: 10.1021/bc100351n

Zhuang, L. F., Jiang, H. H., Qiao, S. C., Appert, C., Si, M. S., Gu, Y. X., et al. (2012). The roles of extracellular signal-regulated kinase $1 / 2$ pathway in regulating osteogenic differentiation of murine preosteoblasts MC3T3-E1 cells on roughened titanium surfaces. J. Biomed. Mater. Res. A. 100A, 125-133. doi: 10.1002/jbm.a.33247

Conflict of Interest Statement: The authors declare that the research was conducted in the absence of any commercial or financial relationships that could be construed as a potential conflict of interest.

Received: 24 January 2014; accepted: 07 May 2014; published online: 27 May 2014. Citation: Sitasuwan P, Lee LA, Li K, Nguyen HG and Wang Q (2014) RGDconjugated rod-like viral nanoparticles on $2 D$ scaffold improve bone differentiation of mesenchymal stem cells. Front. Chem. 2:31. doi: 10.3389/fchem.2014.00031

This article was submitted to Chemical Biology, a section of the journal Frontiers in Chemistry.

Copyright (c) 2014 Sitasuwan, Lee, Li, Nguyen and Wang. This is an open-access article distributed under the terms of the Creative Commons Attribution License (CC BY). The use, distribution or reproduction in other forums is permitted, provided the original author(s) or licensor are credited and that the original publication in this journal is cited, in accordance with accepted academic practice. No use, distribution or reproduction is permitted which does not comply with these terms. 